\title{
Methodology of the ROA information system on occupational groups and types of education
}

Citation for published version (APA):

de Grip, A., Borghans, L., \& Willems, E. (1995). Methodology of the ROA information system on occupational groups and types of education. Researchcentrum voor Onderwijs en Arbeidsmarkt, Faculteit der Economische Wetenschappen. ROA Working Papers No. 1E https://doi.org/10.26481/umarow.199501E

Document status and date:

Published: 01/01/1995

DOI:

10.26481/umarow.199501E

Document Version:

Publisher's PDF, also known as Version of record

\section{Please check the document version of this publication:}

- A submitted manuscript is the version of the article upon submission and before peer-review. There can be important differences between the submitted version and the official published version of record.

People interested in the research are advised to contact the author for the final version of the publication, or visit the DOI to the publisher's website.

- The final author version and the galley proof are versions of the publication after peer review.

- The final published version features the final layout of the paper including the volume, issue and page numbers.

Link to publication

\footnotetext{
General rights rights.

- You may freely distribute the URL identifying the publication in the public portal. please follow below link for the End User Agreement:

www.umlib.nl/taverne-license

Take down policy

If you believe that this document breaches copyright please contact us at:

repository@maastrichtuniversity.nl

providing details and we will investigate your claim.
}

Copyright and moral rights for the publications made accessible in the public portal are retained by the authors and/or other copyright owners and it is a condition of accessing publications that users recognise and abide by the legal requirements associated with these

- Users may download and print one copy of any publication from the public portal for the purpose of private study or research.

- You may not further distribute the material or use it for any profit-making activity or commercial gain

If the publication is distributed under the terms of Article $25 \mathrm{fa}$ of the Dutch Copyright Act, indicated by the "Taverne" license above, 


\section{Methodology of the ROA information system on occupational groups and types of education}

Andries de Grip, Lex Borghans, Ed Willems

ROA-W-1995/1E

A previous version of this paper is presented at the Economic Commission for Europe (ECE) Work Session on Demographic Projections, Eurostat, Luxembourg, 1-4 June, 1994

Research Centre for Education and the Labour Market

Faculty of Economics and Business Administration

University of Limburg

Maastricht, January 1995 


\section{CIP-GEGEVENS KONINKLIJKE BIBLIOTHEEK, DEN HAAG}

Grip, Andries de

Methodology of the ROA information system on occupational groups and types of education / Andries de Grip, Lex Borghans, Ed Willems. - Maastricht : Research Centre for Education and the Labour Market, Faculty of Economics and Business Administration, University of Limburg. - ([Working paper] / Research Centre for Education and the Labour Market, ISSN 0922-4645; ROA-W-1995/1E)

With ref.

ISBN 90-5321-153-5

Subject headings: labour market ; information systems / education ; information systems. 


\section{Contents}

\section{Page}

1 Introduction

2 Data sources and classifications

3 Expansion demand forecasts

4 Replacement demand forecasts

5 Forecasts of inflow of school-leavers

6 Labour market indicators

7 Conclusions and further research

References 


\section{Introduction}

In the 1960s the manpower requirement approach was used as a planning instrument (see e.g. Parnes, 1962). One response of the advocates of this approach to severe criticism of its usefulness for planning purposes was to change the function of manpower forecasts to the generation of information for the various participants on the labour market (see Hollister, 1965 and Van Eijs, 1993). The forecasts therefore have primarily an informational function. It is in this context that the Information System on Education and the Labour Market has been developed by the Research Centre for Education and the Labour Market (ROA). This information system focuses on increasing the transparency of the match between education and the labour market. A special effort is made to generate information on the labour market prospects of occupational groups and the graduates from various types of education. This information is primarily intended to assist young people in choosing an occupation or training course.

ROA seeks to realize this transparency of the match between education and the labour market by providing a differentiated, representative and coherent picture of the educational and occupational structure of the labour market, and of current developments. The information provided by the information system is primarily intended to be used in relation to educational and vocational choices, the implications of which will only be apparent in the labour market at the end of training courses which often last for several years. Therefore the system focuses on data on the future labour market prospects of occupational groups and types of education, in addition to information on the current labour market situation. The system also contains indicators on the structural labour market risks that are associated with certain occupational groups and/or types of education. These relate to information on the width of the occupational domains to which these educational varieties are directed and the cyclical sensitivity of employment in the occupations which can be practised with each type of education. With these elements of the information system, ROA also tries to achieve a synthesis between the manpower forecasting approach and the labour market flexibility approach. The latter approach is followed particularly by the German Institut für Arbeitsmarkt und Berufsforschung (IAB) (see e.g. Sheldon, 1985).

In developing the methodology for drawing up labour market forecasts, a link was sought with the old familiar manpower requirements approach. This approach is today more promising than in the past, because of the more regular availability of labour market data from the Labour Force Survey. Realizing that labour market forecasts are never perfect, ROA bore a number of principles in mind in developing the information system:

-The forecasts will for the time being be limited to the medium term, that is, for a period of about five years. Within this horizon, changes in the labour market are less uncertain than in the long term and the forecast results will still be appropriately usable for those choosing 
a course of study which will last some years.

-The forecasts should focus on the job openings for newcomers on the labour market, differentiated by occupation and education. The main emphasis should be on forecasts of the labour market prospects by educational category, based on confrontations of demand and supply forecasts.

-The forecasts must be compatible with existing forecasts of employment changes for each economic sector, which are prepared by the Dutch Central Planning Bureau (CPB), and the forecasts of flows from education made by the Ministry of Education and Science.

-Instead of fixed coefficients for the occupational and educational structures of employment, explanatory models should be used as much as possible, in an attempt to take shifts in these structures over time into account.

-No detailed comparison of demand and supply for each forecasting year should be given, but rather an impression of the broad relations between developments in demand and supply over the entire forecasting term, by means of a qualitative categorization of labour market prospects.

-The forecasts should be drawn up every two years, so as to keep pace with developments. Observed differences between forecasts and outcomes can then be used to improve the forecasting approach.

-The forecasts should be supplemented with labour market indicators that give an idea of the labour market risks of occupational groups and types of education (alternative job possibilities on the labour market, cyclical sensitivity).

Given these basic principles, the methodology for forecasting changes in employment levels is as follows. The medium term forecasts of the working population for each of 14 sectors of the economy, made by the CPB, are taken as the starting point. Then forecasts are made of the shifts in the occupational structure of employment in the various sectors. Finally, taking into account the expected shifts in the occupational structures of industries and occupations, the employment forecasts for the different types of education are determined. This approach guarantees that the educational and occupational employment forecasts are consistent with the CPB forecasts of employment by sectors.

Figure 1 gives an overview of the forecasts used in the information system on education and the labour market. The occupational model that underlies the forecasts of the occupational structure of employment assumes that the occupational structure of a sector is an aspect of the demand side of the labour market. Changes in the occupational structure of employment in each sector are therefore explained in the model by factors which primarily influence the demand for labour. The educational model on the other hand assumes that the educational structure of an occupation may be influenced by demand as well as supply factors.

In general the future replacement demand due to the departure of personnel is more important in determining the number of jobs that become available for new entrants on the labour market 
than the increases in employment levels. The replacement demand is on the one hand the result of permanent withdrawals from the labour force because of reaching retirement age or taking early retirement, and on the other hand the result of often temporary withdrawals, especially by married women who care for and raise their children. The replacement demand is therefore closely related to the age structure and sexual composition of occupations and types of education. In forecasting the replacement demand these two factors therefore play an important role.

The forecasts of the influx of school leavers are based on external estimates from the Ministry of Education and Science. These forecasts are completed by incorporating figures for nonregular initial and adult vocational education and then disaggregated to the more detailed classification of types of education which is used in the information system.

For each occupational class and type of education, the employment forecasts are combined with the forecasts of replacement demand, to produce the number of expected future job openings. For the types of education, this figure is matched with the number of school leavers entering the market plus the number of short-term unemployed at the beginning of the forecasting period, to indicate their labour market prospects.

In this paper the methods for determining the demand and supply forecasts in the most recent version of the ROA information system will be elaborated and explained. These forecasts refer to the period 1993-1998 and are published in The Labour Market by Education and Occupation to 1998 (ROA, 1993). In section 2 the basic data and classifications which are used will be briefly described. Section 3 discusses the forecasts of expansion demand by occupational classes and types of education, and section 4 deals with the forecasts of replacement demand. Section 5 indicates how the forecasts of the flow of school leavers onto the labour market from the different types of education are drawn up. The way in which the correlation of these inflows with the job openings is made is explained in section 6 . This section also discusses two labour market risk indicators. Finally in section 7 some conclusions are drawn. 
Figure 1

Forecasts in the information system on education and the labour market

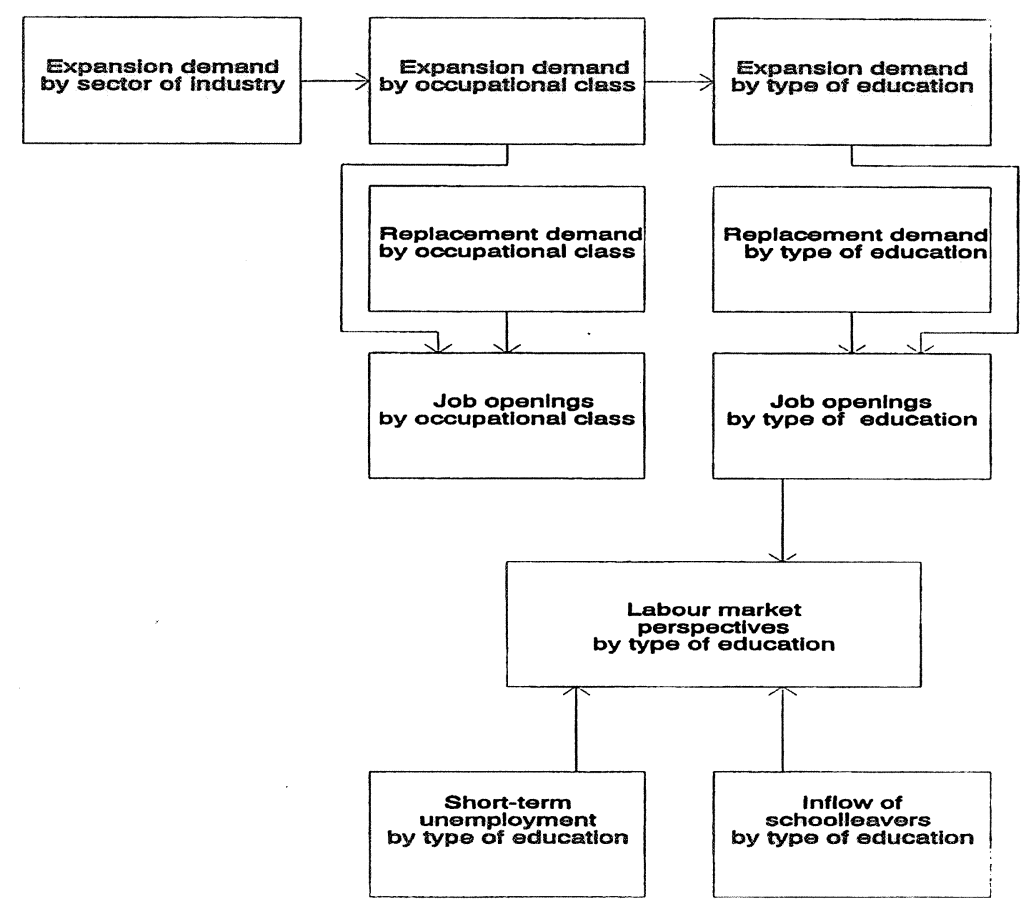

\section{Data sources and classifications}

In the employment model 14 economic sectors are distinguished. These correspond with the economic sector classification used in the Athena model, with which the CPB makes forecasts of medium term changes in the labour volume and the numbers of workers for each sector (CPB, 1990). The classification corresponds to the standard industry classification of the Statistics Netherlands (CBS). The data on each sector which is used in the Athena model and by ROA, such as the employment levels, the level of investment and the value added, are obtained from the CPB.

The data on employment by occupational classes and types of education is expressed in terms of numbers of workers. This data, further differentiated by sector, age and sex, is taken from the Labour Force Survey (AKT) of the CBS. The Labour Force Surveys are random 
samples of 2.5 to $5 \%$ of the total labour force. They were undertaken every two years till 1985 . After that the CBS changed to a somewhat smaller continuous random sample of about $1 \%$ of the labour force, the so-called EBB. However, this gives usable data only after $1988 .{ }^{1}$ Together, these data sources enable us to construct a time series with biannual data from 1979 to 1985 and comparable annual data from 1988 to 1992.

The main sources of data for the forecasts of the flows of school leavers are the so-called 'Reference projections', which are compiled by the Ministry of Education and Science. Various other data sources have also been used: the 'Complete student count' for secondary education and apprenticeship training, the educational matrix of students flows, and miscellaneous data sources on students in (adult) education. Unemployment rates are based on the official data from the CBS and disaggregated by means of data on registered unemployment from the Employment Offices.

A total of 93 occupational classes are distinguished. These were originally based on the 320 three-digit occupational groups according to the standard occupational classification of the CBS, which in turn links up with the international ISCO-68-code. ${ }^{2}$ Using a statistical cluster procedure and other methods, ROA consolidated these 320 occupational groups into 93 classes and then into 48 segments which are as homogenous as possible as regards their training structures (De Grip, Groot and Heijke, 1991 and Van de Loo, Dekker and De Grip, 1992).

Altogether 49 educational categories are distinguished. This classification was taken from the three-digit classification of the Standard Education Classification (SOI) of the CBS, which links up with the ISCED-code. The first digit of the original SOI code refers to the educational level, ranging from 2 (Primary Education) to 6 (Academic Education). The various fields of study, such as 'general', 'technical' or 'medical', are indicated by the second and third digits of the same code.

\section{Expansion demand forecasts}

The expansion demand forecasts are probably the most difficult element of ROA's information system on education and the labour market. This section will describe the construction of the model that is used for the medium-term forecasts for occupational classes and types of education up to 1998. Figure 2 gives an overview of the structure of the ROA employment

1.Reliable EBB data classified by type of education is only available as of 1990. The Labour Force Surveys from 1975 and 1977 have not been used for generating information on types of education, due to the introduction of a new educational classification in 1978.

2.Recently the CBS introduced the 'Standaard Beroepenclassificatie 1992', which is linked with the new ISCO-88-code. 
forecasts. In contrast to the traditional manpower-requirements approach, no fixed relations between occupations and types of education are assumed. As in some earlier studies by ROA, a somewhat more flexible relationship is assumed based on explanatory variables for the changes in both the occupational and educational structures of employment.

The employment projections by sector which are made by the CPB with the help of their Athena model are the starting point for the forecasts. This means that the more detailed forecasts, which distinguish the prospects of particular types of education and occupations, are consistent with the broadly accepted macro-economic and economic sector forecasts of the CPB. On the basis of these CPB forecasts the average expansion demand for 1993-1998 is forecast at $0.7 \%$ per year, with sectoral growth varying from a fall in employment levels of $0.5 \%$ per year in the agriculture, fisheries and forestry sector to an annual growth in employment of $1.9 \%$ in non-commercial services.

The Athena model of the CPB is a multi-sector model of the Dutch economy which distinguishes 14 sectors (CPB, 1990). For each sector a clay-clay production function with heterogeneous vintages (annual cohorts) is used. Disequilibrium may arise in the production process and the labour market, which then feeds back into prices, wage rates, investment, the demand for labour, etc. The employment equation for the industrial sectors is derived from the model for production capacity and consists of three parts. One part describing the vintage effect on labour volume, one part describing the 'disembodied' changes in the number of jobs and one part describing short-term adaptation processes. The employment level equations for the remaining economic sectors are not derived from a formal production function but were formulated ad hoc on the basis of studies for each sector.

Starting from the CPB forecasts of employment by sector, a two-step model is estimated to explain the occupational structure of the sectors. The changes in employment levels per economic sector are first translated into employment changes per occupational segment. Then the forecast of expansion demand is further disaggregated by occupational classes. As noted in section 1, the assumption in the design of the occupational models is that the occupational structure of a sector is entirely determined by the demand side of the labour market. Changes in the demand per occupational class are determined by shifts in employment between economic sectors and changes in the occupational structure of the employment per economic sector. 
Figure 2

Structure of the expansion demand forecasts

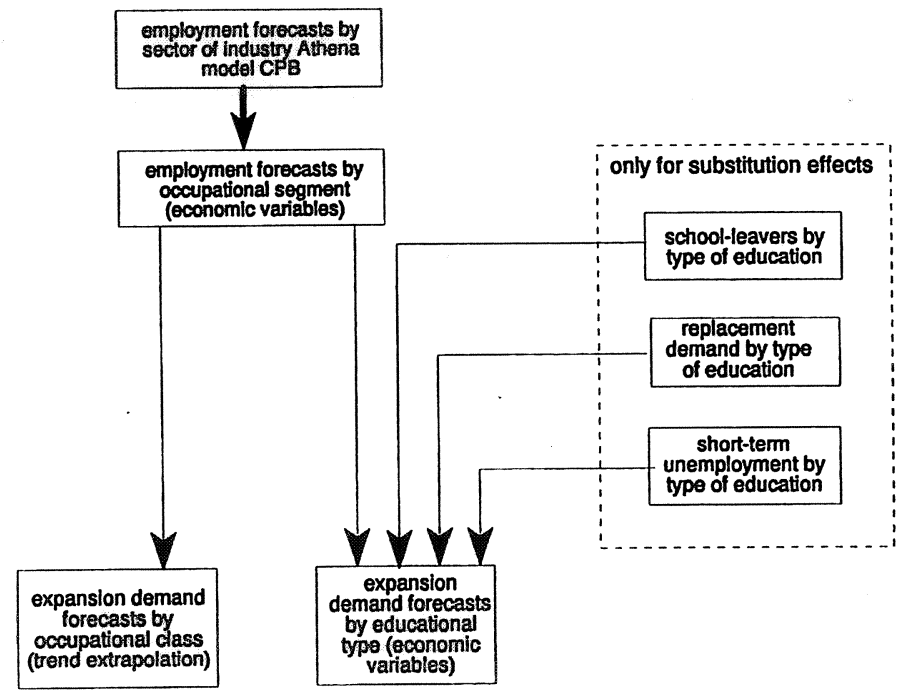

Changes in the employment structure are estimated on the basis of the AKT and EBB data of $1979,1981,1983,1985,1988,1989,1990$ and 1991. In accordance with the new definition of the working population this data relates to people working at least 12 hours per week. Because the available time series is rather short, in earlier versions of the occupational model it proved difficult to get reliable parameter estimates which would indicate reasonably stable future developments.

In order to get more reliable parameter estimates without affecting the specificity of the separate occupations, a random coefficients model has been used. ${ }^{3}$ In this random coefficient model each parameter value is a weighted average of, on the one hand, the average parameter value over all the pooled occupations and, on the other hand, estimates for each separate occupation. The weighting is determined by the accuracy of the two components. If there is a great deal of variation between the various occupations, a pooled estimate is relatively inaccurate and more weight is placed on the separate estimates. However if these separate estimates have a high standard error, their weighting is reduced. Thus an optimal combination is found between the information in the pooled data and in the separate estimates.

There have been changes not only in the estimation techniques, as compared to the approach

3.Borghans and Heijke (1994) provide a detailed description of this model. 
used in earlier versions of the information system (see Dekker, De Grip and Heijke, 1990), but also in the specification of the equation. A specification which forecast employment levels has now been replaced with one which forecasts growth. In the earlier method, a regression equation was estimated on the basis of the shares of particular occupations in employment in each economic sector. If, in the most recent year for which observations were available, this share was much larger or smaller than in the previous years, this was implicitly treated as an anomaly. But by forecasting growth, the implicit assumption is that these unexplained changes in employment levels will continue in the future. However, because an explanatory model of the occupational structure will always be insufficient, it is better to treat such anomalous results as an indication of unexplained changes which will continue to have their effects in the future.

For each economic sector, the following specification is taken as a starting point:

$\dot{a}^{o s}=\dot{a}^{s}+\beta_{1}^{o s} t+\beta_{2}^{o s} \dot{Y}^{s}+\beta_{3}^{o s} \dot{H} O U R+\beta_{4}^{o s} \dot{U} R+\varepsilon^{o s} 1$

where:

$\dot{a}^{o s} 2=$ the growth rate of occupation $o$ in economic sector $s ;$

$\dot{a}^{s} 3=$ the rate of growth in the total number of people working in economic sector $s$.

$t \quad=$ the number of years between two successive observations. The parameter value of $\mathrm{t}$ thus indicates the constant growth rate per year.

$\dot{Y} 4$ =growth in the capacity of production. In the industrial economic sectors this is determined by calculated how many labour years of labour input would be required if the present physical capacity was fully utilized (i.e., current employment divided by the utilization ratio $\left(\dot{y}^{*} 5\right)$ ). For the other sectors this definition is replaced with the gross added value at factor costs (for the construction industry, domestic deliveries excluding imports), $\dot{y} 6$.

$\dot{H O U R} 7$ =the growth in the hours per year worked under employment contracts.

$\dot{U} R 8=$ the unemployment rate.

It is assumed that the vector $\beta^{o s}=\left(\beta_{1}^{o s}, \ldots, \beta_{4}^{o s}\right) 9$ is normally distributed:

$\beta^{o s}-N\left(0, \Sigma^{s}\right) 10$

Each parameter is thus specific for each occupation (o) in each economic sector (s) but, because of the random coefficient structure (3.2), there is a reciprocal link between the parameters of the various occupations in the same economic sector. However, not every explanatory variable is used in every economic sector. The explanatory variables correspond to those used in the Athena model of the CPB. Table 1 shows which explanatory variables are used for each economic sector. Relative wage costs are not included in the model, for lack of adequate data. Consequently, it is assumed that the wage structure as such does not change, or that the influence of the wage structure on the occupational structure of employment within economic sectors is constant. 
Table 1

Overview of the explanatory variables per economic sector

economic sector

explanatory variables used

t $\quad \dot{y}^{*} 11 \dot{y} 12 \dot{H} O U R 13$

$\dot{U} R 14$

Agriculture, fisheries and forestry

Food and beverages industry

Chemicals

Metal, electrical, and transport requirements industries

Other industry

Energy

Construction

Commerce

Transport and communication

Other commercial services

Non-commercial services

Government, police, defense and education

$\begin{array}{llll}\mathrm{x} & & & \mathrm{x} \\ \mathrm{x} & \mathrm{x} & & \mathrm{x} \\ \mathrm{x} & \mathrm{x} & & \mathrm{x} \\ \mathrm{x} & \mathrm{x} & & \mathrm{x} \\ \mathrm{x} & \mathrm{x} & & \mathrm{x} \\ \mathrm{x} & & & \mathrm{x} \\ \mathrm{x} & & \mathrm{x} & \mathrm{x} \\ \mathrm{x} & & \mathrm{x} & \\ \mathrm{x} & & \mathrm{x} & \\ \mathrm{x} & & \mathrm{x} & \mathrm{x} \\ \mathrm{x} & & \mathrm{x} & \mathrm{x} \\ \mathrm{x} & & & \end{array}$

Because the method described above led in some instances to implausible results, some ad hoc modifications have been made to this general structure. The first modification is for the sector 'Other commercial services', which includes both the banks and insurance companies and other commercial services. The result is that this economic sector is rather heterogenous. In the past the banks and insurance companies have experienced strong growth, which implies that the occupational segments which are linked to these economic sectors have also enjoyed strong growth. In the estimates this is expressed in high parameter values for the trend variable for these occupational segments. This growth would therefore also be forecast for the coming years, but the CPB, in its more specific sector forecasts, expected a reduction in the employment growth in the banking and insurance sector. The methodology which has been used would mean that retrenchment in the economic sector, which is caused by the banks and insurance companies, would affect all occupational segments, and moreover that the shares of the occupational segments which are most strongly represented in banking and insurance would increase because of their past growth. In order to prevent implausible results for the economic sector 'Other commercial services', the constant term here is replaced, as a trend variable, by the growth and forecast growth for the banking and insurance sector. The result is that the occupational segments which have enjoyed strong growth in the past, presumably due to the growth of these business, are forecast to suffer greater cuts than the other occupational segments in coming years.

A second modification to the general method described above relates to the occupational segment 'Government, police, defense and education'. Since the government as a whole will, according to the CPB, suffer retrenchment, this would also apply to police numbers. But in fact 
the government has excluded any cuts in these occupational groups. Therefore the number of people working for the government in this occupational segment has been assumed to be constant.

Because of the conservative character of the forecasting technique which has been used, it did not appear necessary to make more ad hoc modifications. It would appear very important that, in the future, solutions should be found for the high heterogeneity of the economic sector 'Other commercial services', in particular. Separating out the banks and insurance companies would, in this respect, be a marked improvement.

The forecasts of expansion demand per occupational segment are further dissagregated to forecasts per occupational class. This takes place in a model with a structure similar to that of the model for occupational segments. The difference between the growth of an occupational class and growth in the occupational segment is estimated, with the constant term as the only explanatory variable for growth. This estimation also employs a random coefficient model. The expansion demand in the period 1993-1998 varies, for the various occupational classes, between $-3.8 \%$ per year for 'Textile production workers' to $1.9 \%$ for the occupational class 'Directors, managers and supervisors in manufacturing'.

\section{The educational model}

In earlier versions of the forecast model of the information system, the forecasts of the expansion demand per type of education were derived from the occupational forecasts in a way analogous to the occupational model (see Beekman et al., 1991). The assumption that the demand for labour per occupational segment is independent of supply factors is reasonably plausible, but at the level of types of education allowance must be made for the fact that the actual employment per type of education depends on supply factors.

For instance, in a labour market with high unemployment the competition for jobs may be such that more highly qualified workers displace the less skilled from their 'occupational territory'. The result of this 'crowding-out' (see Teulings and Koopmanschap, 1989) is that persons with a high level of education occupy jobs previously held by persons with a lower level of education. Consequently tensions arise between the ex ante demand per type of education before the demand has adjusted to the supply and the ex post demand for labour, after these adjustments. The ex ante demand is most suitable for ascertaining the tension which may be expected between demand and supply. The adjustments which take place later will in fact be an expression of these tensions between demand and supply. However, it is the ex post demand which is observed in the data.

Economists may prefer the classical or neo-classical procedure, by which the phenomenon of displacement is described with the help of the relative scarcity of a certain level of education 
as expressed in relative wages (see also CPB, 1987). However, for lack of adequate information about the wages earned by persons with a given education, it is necessary to resort to an approximation for the influence of wage factors.

By basing the historical demand in the training model on actual employment levels, any demand and supply factors are incorporated. This would mean that an increase in employment as the result of an increased supply could be interpreted as an increase in the ex ante demand. This would lead to an under-estimation of the tension between demand and supply. To avoid this confusion between demand and supply factors, a model has been developed in which the distinction between the ex ante and ex post demand for labour is explicitly taken into account (see Borghans and Heijke, 1993). To enable these two separate categories to be identified, allowance is made in this model for mutual substitution between types of education.

Figure 3 shows the construction of the training model. The ex ante demand per type of education (e) per occupational segment (o) is determined by the distribution of the types of education in this occupational segment in the most recent year for which observations are available. Because of downward displacement and concentration around the average training level, the ratios between the shares of the various types of education in an occupational segment shift as follows:

$\bar{a}_{o e}=a_{o e}^{t-1} e^{\left(-\gamma_{1}\left(6-l_{e}\right)\right)} e^{\left(-\gamma_{2} l_{e}-l_{o}^{t-1}\right)} 15$

where:

$\bar{a}_{o e} 16=$ number of people with education $e$ in occupation $o$ according to the adjusted training structure;

$a_{o e}^{t-1} 17=$ number of people with education $e$ in occupation $o$ in the base year $t-1$;

$l_{e} 18$ =the level of education $e$ ( 2 for primary education to 6 for academic education);

$l_{o}^{t-1} 19=$ the average level of the types of education in occupation $o$ in the base year $t-1$;

$\gamma_{1} 20=$ coefficient indicated the extent of downward displacement in a 5-year period;

$\gamma_{2} 21=$ coefficient indicating the average degree of concentration for a 5 -year period.

If the supply of a type of education is greater than the demand, the labour market position of that type of education will, according to this model, deteriorate. As a result, newcomers on the labour market will have to switch to other jobs and accept less attractive jobs. The assumption is that the degree of switching to other jobs is proportional to the job structure of this type of education in the previous period. Because the total demand per occupational segment is assumed to be constant, flows of people with one type of education into the labour market automatically mean that other types of education will be displaced. Once again it is assumed that these outflows are proportional to the training structure of this occupational segment. But this displacement means an increase in the discrepancy between demand and supply for the types of training concerned. By reiterating this process a number of times an equilibrium 
situation is found, indicating the ex ante demand with substitution.

This expansion demand with substitution indicates how great the demand for school-leavers with a given educational background is, if no allowance is made for the extent to which people with this type of education adjust to the labour market situation, but allowance is made for the increase or decrease in demand as a result of displacement by other types of education. The reason for this is that adjustments made by people with a particular type of education would in themselves already indicate a worsening in their situation (at least, in the event of an excess of supply). If the post-adjustment employment level is subtracted from the excessive supply, these worsened prospects would be under-estimated. But the reduction in employment opportunities as a result of adjustments made by people with other types of education does mean that employment possibilities are worse, so this component must be incorporated in the ex ante demand.

For the forecasts of the expansion demand per type of education, only the ex ante demand is used, without substitution by other types of education. The equation is estimated on the basis of the non-linear least squares method using data for the years $1979,1981,1983,1985,1990$ and 1991. 
Figure 3

Components of the demand for labour per type of education



Table 2

Estimation results for equation (3.3)

Parameter parameter estimates

t-value

$\gamma_{1} 22$ degree of downward displacement

0.09

$\gamma_{2} 23$ concentration around average training level 0.01

There have also been some modifications made in the basic version of the educational model. In the first place, displacement on the basis of training level has been excluded for both the 'higher educational occupations' and the 'higher medical and paramedical occupations'. This is to prevent doctors in the model taking over the tasks of nurses, or secondary-school teachers taking over the occupation of junior-school teachers. In fact, in these occupational segments the occupational classification is not sufficiently differentiated for the model to be used without modifications.

The second modification relates to 'Police, fire and security officers'. In the existing 
occupational structure, a rather wide range of types of education is still to be found in this occupation, because in the past there was no type of education devoted to the security profession. In the current situation new jobs in this area would be expected to be filled mainly by people with an appropriate educational background. For this reason the displacement coefficient for these types of education and this occupational segment has been set at a very high level, 2.

\section{Replacement demand forecasts}

Replacement demand is an important component of the future demand for newcomers on the labour market (see De Grip, Meyboom and Willems, 1994). It can be the result of permanent departures from the labour force due to retirement, early retirement, other temporary withdrawals such as married women stopping work due to birth and child-rearing, etc. Replacement demand for a particular occupational category can also be due to occupational mobility. As in the previous section we will describe first the methodology used in the forecasts of replacement demand by occupational class and then by type of education.

\section{Occupational classes}

Figure 4 is an input-output table for the entire population, in which these mobility processes are schematically reproduced at an aggregated level (see also Willems and De Grip, 1993). The inner part of the input-output table contains the mobility flows within the labour market. Some of these flows are indicated by the capital letters $A$ to $G$. 'Flow' $A$, indicates the number of employees that kept working in occupation 1 during the period $(t-n, t)$. Flows $B$ and $E$ represent job-to-job mobility. Flows $C$ and $D$ represent departures from employment, to unemployment and non-availability respectively. The latter indicates changes such as retirement and the voluntary exit of, in particular, married women. The unemployed who have found a job during the period $(t-n, t)$ are indicated by the letter $F$. Finally, flow $G$ refers to new positions gained by those who were not available for the labour market at time $t-n$, such as school-leavers who find a job and women who re-enter the labour market.

The replacement demand should be defined in relation to changes in the level of employment. Where there is an increase in employment, the replacement demand is equal to the number of workers who leave a certain job during the period $(t-n, t)$. The vacancies that thus appear will have to be filled before there can be a rise in the total numbers employed. If there is a decrease in employment, not all of the vacancies created by departing employees are filled. Therefore the replacement demand is then not equal to the total number of the departures from a certain job, but rather to the number of vacancies that are actually refilled, that is, the total inflow of labour to the job in question. The concept of replacement demand can be explained further using figure 4 . If there is an increase in employment, the replacement 
demand for occupation 1 is equal to the sum of the flows $B, C$ and $D$ (the total outflow). However, if employment in occupation 1 decreases, the sum of the flows $E, F$ and $G$ (the total inflow) gives the replacement demand.

\section{Figure 4}

Input-output table of labour market flows

\begin{tabular}{|c|c|c|c|c|c|c|}
\hline$t-n$ & Occupation 1 & ... Occupation $I$ & Unemployed & $\begin{array}{l}\text { Outside } \\
\text { labour force }\end{array}$ & $\begin{array}{l}\text { Outflow } \\
\text { population }\end{array}$ & Total \\
\hline $\begin{array}{c}\text { Occupation } 1 \\
\cdot \\
\cdot \\
\cdot \\
\text { Occupation I }\end{array}$ & $\begin{array}{l}\mathrm{A} \\
\mathrm{E} \\
\mathrm{E}\end{array}$ & B & C & D & & $\begin{array}{l}\mathrm{w}_{1 \mathrm{t}-\mathrm{n}} \\
\cdot \\
\cdot \\
\mathrm{w}_{\mathrm{It}-\mathrm{n}}\end{array}$ \\
\hline $\begin{array}{l}\text { Unemployed } \\
\text { Outside } \\
\text { labour force }\end{array}$ & $\begin{array}{l}\text { F } \\
\text { G }\end{array}$ & & & & & \\
\hline $\begin{array}{l}\text { Inflow } \\
\text { population }\end{array}$ & & & & & & \\
\hline Total & $w_{1 t}$ & $w_{I t}$ & & & & \\
\hline
\end{tabular}

Source: Willems and De Grip (1993)

The first step in modelling future replacement demand per occupational class is a description of the inflow and outflow patterns by occupational class in a historical period. Because there is no appropriate data for mobility flows on the labour market, stock data is used. By means of the so-called cohort components method we calculate cohort-change rates based on the number of persons of the same birth cohort who were employed at two different times (see Shryock and Siegel, 1980). These cohort-change rates can be rewritten as average annual net inflow or outflow percentages. ${ }^{4}$

$$
{ }_{k} \dot{W}_{o, a}^{t, n}=\sqrt[n]{\frac{{ }_{k} W_{o, a+n}^{t}}{{ }_{k} W_{o, a}^{t-n}}}-1
$$

${ }_{k} \dot{W}_{o, a}^{t, n} 25$ =the average annual net inflow or outflow ratio of workers in occupational class $o$ of age group a (with class-width $k$ ) at time $t-n$ during the period $(t-n, t)$;

4.Flow rates for male and female workers are differentiated. 
${ }_{k} W_{o, a}^{t} 27$ =the number of workers in occupational class $o$ of age group a (with class-width $k$ ) at time $t$.

If ${ }_{k} \dot{W}_{o, a}^{t, n}>028$ there is a net inflow for a certain age group from an occupational class, and if ${ }_{k} \dot{W}_{o, a}^{t, n}<029$ there is a net outflow.

The second step in modelling replacement demand is the translation of these inflow and outflow percentages into the replacement demand by occupational class. As stated above, for occupational classes with an increase in employment in the period $(t-n, t)$, replacement demand is equal to total net outflow in this period. However, for occupational classes which faced a decrease in employment, not all vacancies due to the outflow of workers will have been filled. Therefore replacement demand for these occupational classes equals the number of vacancies that were actually refilled, that is, the total inflow of workers in the occupational class. In this way the more or less 'structural' replacement demand is derived.

This methodology measures only the net flow to or from an occupational class. This means that replacement demand satisfied by re-entering workers of the same age cohort is not measured. So replacement demand is actually measured for newcomers on the labour market. However, this is exactly what is intended, in as much as the ROA information system focuses on the prospects for newcomers on the labour market.

The third step is to project the historically measured net replacement demand rates per agesex group for a particular occupational class onto the age-sex structure of the workers at the beginning of the forecasting period. Moreover, the historically observed cohort change rates are corrected for business cycle effects and for expected changes in participation rates. The business cycle correction is equal to the difference between the change in the total number of working persons and the change in the labour force in the historical period. This correction offsets the outflow of workers who become unemployed due to cyclical fluctuations in employment levels. The correction for changes in the participation rate is the difference between the growth in the labour force in the historical and the forecasting period. Both correction factors are sex and age specific.

If the cyclical correction and the participation rate correction are combined, the forecast future outflow ratio by age category will be:

$$
\begin{aligned}
{ }_{k} \dot{W}_{o, a}^{t, m}={ }_{k} \dot{W}_{o, a}^{t, n}+{ }_{k} \dot{L} F_{a}^{t, n}-{ }_{k} \dot{W} P_{a}^{t, n}+{ }_{k} \dot{L} F_{a}^{t, m}-{ }_{k} \dot{L} F_{a}^{t, n} \\
={ }_{k} \dot{W}_{0, a}^{t, n}{ }_{k}{ }_{k} \dot{W} P_{a}^{t, n}+{ }_{k} \dot{L} F_{a}^{t, m}
\end{aligned}
$$

where:

${ }_{k} \dot{W}_{o, a}^{t, m} 32$ =the expected average annual net inflow or outflow ratio of workers in occupational class $o$ of age group a (with class-width $k$ ) at time $t$ during the forecast period ( $t$, $t+m)$;

${ }_{k} \dot{L} F_{a}^{t, n}$ 33=the average annual growth ratio of the total labour force of age group a (with class- 
width $k$ ) at time $t-n$ during the period $(t-n, t)$;

${ }_{k} \dot{L} F_{a}^{t, m} 34 \quad=$ the expected average annual growth ratio of the total labour force of age group $a$ (with class-width $k$ ) at time $t$ during the forecast period $(t, t+m)$;

${ }_{k} \dot{W} P_{a}^{t, n} 35 \quad$ =the average annual rate of growth of the total number of working persons of age group a (with class-width $k$ ) at time $t-n$ during the period $(t-n, t)$.

Future replacement demand is further determined in the same way as replacement demand in the historical period. That means that for occupational classes with an expected increase in employment, replacement demand equals net outflow. For occupational classes for which a decrease in employment is expected, replacement demand is equal to the total net inflow.

In compiling the forecasts for the period 1993-1998 it was possible to use data differentiated by sex and age category ${ }^{5}$ for the number of workers per occupational class, and per type of education, for the years $1981,1985,1990,1992$. On the basis of the data, the cohort change rates for three periods (1981-1985, 1985-1990 and 1990-1992) were determined. By then averaging these ratios and also making allowance for the business cycle correction and participation rate correction described above, one obtains the net inflow or outflow coefficients which can be expected for the forecast period, on the basis of which the replacement demand can be determined.

The replacement demand for six occupational classes had to be adjusted because one or several of the calculated net turnover coefficients had a value which, when extrapolated, would lead to implausible results. This arises when relatively large growth in a given age group which has been observed in the past is extrapolated. However, in a group which has grown to be large in the forecasting period, such high growth rates are improbable, because it would imply an unrealistic 'forecast' age structure of that workforce. On the basis of the most recent data available (1992), the age structure is adjusted for these occupational classes, over the relevant age categories. The average annual rate of replacement demand found for occupational classes for the period $1993-1998$ is $3.3 \%$, varying from $1.3 \%$ for 'System analysts, programmers, and system supervisors' to $5.8 \%$ for 'Clothing, textile and fur product makers'.

\section{Types of education}

Replacement demand by type of education must be interpreted differently from replacement demand by occupational class, as net mobility between occupational classes must also be taken into account in the latter. However, when a worker with a certain educational background changes occupation, this does not create a vacancy for a newcomer on the labour market with the same educational background. Therefore this does not influence replacement demand for newcomers for the type of education in question.

5. Based on a division into 5-year bands. 
There is another difference between the replacement demand by occupational class and by type of education. If someone leaves a certain occupational class and is replaced by an employee with another (e.g. higher) educational background, there is a replacement demand for the occupational class in question. When such displacement or substitution effects occur, however, there is no question of replacement demand for the type of education in question, but rather of an employment decrease for one type of education and an employment increase for the other.

For five types of education, adjustments have again had to be made to the results found with the aid of the methodology described above. Once again, the historically observed net labour turnover coefficients, if extrapolated, would lead to implausible forecast results. For the types of education 'Intermediate Vocational Education, Non-medical Laboratory' and 'University Education, Agricultural' a correction similar to that for the six occupational classes mentioned above was required. For 'Preparatory Vocational Education, Security' and 'Higher Vocational Education, Interpreter and Translator' there were large differences in the turnover coefficients in the three observation periods of 1981-1985, 1985-1990 and 1990-1992. For a given cohort, a net outflow was measured in one period and a net inflow, for the same cohort, in another period (or vice-versa). If these turnover coefficients are averaged the results are implausible, but if the model calculations are carried out using the turnover coefficients for the three separate periods the outcomes are plausible. It was therefore decided that the final forecast should be based on an average of the three model outcomes. The fifth adjustment relates to the forecast for 'University Education, Fine Arts'. The forecast here, expressed as a percentage of the numbers already working, has been set equal to the replacement demand forecast for 'Higher Vocational Education, Fine Arts'.

As said, the replacement demand per type of education is somewhat lower than the replacement demand per occupational class. The average was $2.8 \%$ per year, with a range from $0.5 \%$ for 'Higher Vocational Education, Business Administration Technology' to $4.9 \%$ for 'Preparatory Vocational Education, Community Care, Hotel and Catering'.

\section{Forecasts of inflow of school-leavers}

For each type of education, forecasts have been made of the potential flow of school-leavers onto the labour market. Several data sources have been used for these forecasts. The Ministry of Education and Sciences makes annual forecasts of the number of school-leavers from full-time and part-time education. These so-called 'Reference projections' are differentiated by sex and age, but they are at a higher level of aggregation than ROA's categorization of types of education (Ministerie van Onderwijs en Wetenschappen, 1993). 
The forecasting model used is based on a transition-matrix based on the composition of fulltime education and a classification of the population by level of education. Flow coefficients relate the 'origin' of students in year $t$ to the 'destination' of these students in year $t+1$. By means of these flow coefficients, future numbers of students from each educational category can be forecast step-by-step. However, such a straightforward approach would suppose that students' choices remain unchanged during the entire forecasting period. Therefore, the flow coefficients of students who get a certain qualification are considered as strategic flow coefficients. These strategic flow coefficients are the dynamic elements of the model as they are determined by (modified) trend extrapolations.

As the Ministry's forecasts of school leavers are at a higher level of aggregation with regard to the types of education, distribution keys are needed to break down these forecasts. These distribution keys are formulated from various additional data sources.

Besides those leaving school with a qualification, the 'Reference projections' cover students who end their studies without a diploma. With the help of the education matrix for 1990, these school-leavers can be re-assigned to any preliminary course from which they had obtained a diploma.

A forecast is also made of the flow from non-regular education (apprenticeships, recognized correspondence courses, training in medical care etc.) onto the labour market. Data about that category has to be taken from available additional statistics, or obtained directly from the training institutions concerned However, enrolment in non-regular courses changes the qualification profile of 'school leavers'. For that reason, the number of students who have successfully completed such courses has to be proportionally subtracted from their preliminary regular educational groups. Another correction is needed to prevent students enroling in several non-regular courses or in a regular and non-regular course of the same type being counted twice. In this way a forecast can be drawn up of the flow from both regular and nonregular educational groups onto the labour market. ${ }^{6}$

For 1993-1998, the average annual total flows of school-leavers entering the labour market vary from $0.6 \%$ of the present workforce for 'Preparatory Vocation Education, Transport and Harbour' to $10.6 \%$ for 'University Education, Fine Arts'.

\section{Labour market indicators}

By matching labour demand with labour supply, an indicator of the future labour market situation' (IFLM) can be constructed. This indicator of labour market prospects is constructed for each of the types of education which are distinguished. As said, labour demand is the sum

6.See Berendsen, et al. (1992) for detailed information about the method and the required data. 
of the expansion and replacement demand, and is characterized using an indicator of the "job openings' by type of education. Labour supply consists on the one hand of the expected inflow in the period 1993-1998 and on the other hand of the number of unemployed with the same educational background who had been unemployed for less than one year in 1993. The exclusion of those unemployed for more than one year is based on the supposition that they do not compete on the labour market with school-leavers with the same type of education.

In formulaic form, the indicator for a specific type of education is as follows:

$$
I F L M=\frac{E_{93}+I N S_{e 93-98}+U_{e} 93}{E_{93}+E D_{e 93-98}+R D_{e 93-98}} 36
$$

where:

$E_{e 93} 37 \quad=$ =employment in type of education $e$ in 1993

$I N S_{e 93-98} 38$ =influx of school leavers with educational background $e$ during the forecast period 1993-1998

$U_{e 93} 39=$ number of people with educational background $e$ that are less than one year unemployed in 1993

$E D_{e 93} 40$ =expected expansion demand for type of education e during the forecast period 1993-1998

$R D_{e 93} 41 \quad=$ expected replacement demand for type of education $e$ during the forecast period 1993-1998

The indicator of the future labour market situation is translated into a "qualitative characterization' of the expected labour market prospects on a 4-point scale: good, reasonable, moderate and poor prospects, respectively. Such a qualitative characterization in quite broad terms suffices for various purposes, including vocational and educational guidance counselling. Moreover, it prevents too much significance being attached to the exact numbers produced by the equation, which also increases the reliability of the forecasts. Altogether the labour market prospects of 12 types of education have been characterized as good, and the prospects for 6 types of education are poor. The latter groups include unskilled workers (primary education only) as well as some academic studies (in arts and agriculture).

\section{Risk indicators}

However, an unfavourable labour market indicator does not automatically mean that school leavers will be confronted with unemployment, any more than a clear demand surplus will automatically lead to unfilled vacancies. The final consequences of a demand or supply surplus depend also on the market position of a particular type of education and occupational class, for instance on whether school leavers can switch to other sectors of the labour market or on the substitution possibilities between the types of education within an occupational class. 
Therefore, in addition to the labour market forecasts, two risk indicators are included in the information system. These risk indicators give an indication of the cyclical sensitivity of employment in a certain occupational class and of the possibilities of switching to another occupation (lateral mobility) or another economic sector (inter-sectoral mobility), indicating the labour market flexibility of the educational type concerned. The trend in the dispersion index is also entered into the information system.

The cyclical sensitivity of occupations is measured as follows (see De Grip and Heijke, 1988). For every economic sector the following fluctuation index is calculated:

$F I_{s}=\frac{100}{H} \sum_{t=1}^{H} \frac{\left|F_{s t}\right|}{T_{s}} 42$

$F I_{s} 43=$ cyclical sensitivity index for economic sector $s$

$F_{s t} 44$ =divergence of employment in economic sector $s$ and year $t$ from the trend value;

$T_{s} 45$ =trend value of employment for economic sector $s$;

$H 46$ =number of observation years.

The trend values are determined by taking the five-year moving average of employment in the sector, over the period 1950-1988.

Supposing that employment in the various occupations within an occupational class fluctuates to the same degree as the total employment in the economic sector, a fluctuation index for each occupation may be derived by weighting the fluctuation-indices of the various sectors by the sector share in the occupational class.

$F I_{o}=\sum_{s=1}^{S} \alpha_{o s} F I_{s}$

$\mathrm{FI}_{0} 48=$ cyclical sensitivity index for occupation 0 ;

$\alpha_{o s} 49=\quad$ share of economic sector $s$ in the number of workers in occupation 0 ;

$S 50=$ number of economic sectors.

For 10 occupational classes the cyclic sensitivity of employment was very high. The various occupations in the construction industry are very much over-represented in this group.

The possibility of lateral mobility for people with a given education to other occupations is calculated by means of the 'Gini-Hirschman' coefficient, as follows (see De Grip and Heijke):

$G H_{e}=\left(1-\sum_{o=1}^{O} \beta_{e o}^{2}\right) \frac{O}{O-1}$

$\mathrm{GH}_{e} 52=$ dispersion index of educational type e;

$\beta_{e o} 53=$ portion of occupational group o in educational type e;

$054=$ number of occupational groups. 
This indicator can have values between 0 and 1 . The value is 0 if the type of education is found in only one occupation, and 1 if people with that type of education are dispersed equally over all occupations. In determining the indicators, only those who are actually working in an occupational group at a level corresponding to their education or a higher level are considered. For 11 types of education there are many opportunities for switching to other occupational groups, while 10 types of education offer only very limited switching opportunities. The latter group relate particularly to training and professional courses for health care and education.

These risk indicators are a very important addition to the labour market forecasts. For example, high occupational dispersion will make medium to long-term forecasts rather conditional, because, in the event of excess supply, it would be expected to be relatively easy for those in this educational group to shift to other segments of the labour market. The cyclical sensitivity indicator may also relativize medium to long term forecasts. If high employment growth is forecast for an occupational class with high cyclical sensitivity, the possibility has to be taken into account that this growth could be sharply reduced in the longer term, or even that it could turn into a decrease in employment.

\section{Conclusions and further research}

In this paper the methodology of the ROA medium-term labour market forecasts of the prospects of occupational classes and educational types has been explained. We have also indicated how two indicators are calculated, relating to the long-term employment risks of the various occupations and educational types. These indicators concerned the cyclical sensitivity of occupations and the opportunities for people with particular types of education to switch to other occupations.

The labour market forecasts and risk indicators are developed in such a way that the information supplied should play an especially useful role in vocational and educational guidance. The extent to which this is really so will be shown by a further evaluation of the use of this information in practice.

In any case it can already be seen that the clustering of educational types used is in many cases insufficiently detailed for enable a direct link to be made between the specific disciplines which pupils choose and their labour market prospects. It has to be asked whether the labour market prospects of students qualified in a specific discipline correspond to those of the educational cluster as a whole. The random-sample basis of the labour market data which we have used, however, makes it impossible to draw up very specific forecasts or to redefine the educational clusters so that the labour market prospects within each cluster would be more homogenous. 
The surveys of the labour market position of secondary school leavers and graduates of higher education which ROA has helped to establish can perhaps contribute to solving this aggregation problem. Moreover, these new data sources could make it possible to extend the ROA information system with new indicators. For instance, information on career path possibilities and perhaps also the pass rates, unemployment durations and the wages of the school-leavers of the different types of education could be added.

The methodology for forecasting labour market prospects which has been developed consists of a logically designed structure of procedures and models. Yet this methodology has not in any sense found its final form. ROA intends to develop model structures in which explanatory models are used at relatively high aggregation levels while simple extrapolation techniques suffice for disaggregating the results. Furthermore, we will examine whether the methods of forecasting the replacement demand and the inflow of schoolleavers can be improved by specifying econometric models in stead of using more or less fixed coefficients. We will also be considering seeking substantive pre-publication comments from the contact persons of institutions with expertise in a particular segment of the labour market. Consideration is also being given to including an indication of the way in which good or bad labour market prospects for a particular type of education would be manifested (in unemployment, wage rates, underutilization etc.).

Finally, attempts will also be made to improve the quality of the base data. In that connection the occupational and educational classification systems will be modified, so that it is possible to define occupational and educational segments which are more homogenous in labour market terms.

\section{References}

Beekman, Th., R. Dekker, A. de Grip, H. Heijke (1991), An Explanation of the Educational Structure of Occupations, Labour, vol. 5, no. 3, pp. 151-163.

Berendsen, H., R.J.P. Dekker, A. de Grip, P.J.E. van de Loo (1992), Prognose arbeidsmarktinstroom schoolverlaters, ROA-W-1992/2, Maastricht.

Borghans, L., H. Heijke (1993), Forecasting the Educational Structure of Occupations: a Manpower Requiremant Approach with Substitution, ROA-RM-1993/2E, Maastricht.

Borghans, L., H. Heijke (1994), Een random-coëfficiënten-model voor het voorspellen van de beroepenstructuur van bedrijfstakken, ROA-W-1994/1, Maastricht.

Central Planning Bureau (1990) ATHENA, een bedrijfstakkenmodel voor de Nederlandse economie, CPB monograph no. 30 , The Hague.

Dekker, R., A. de Grip, H. Heijke (1990), An Explanation of the Occupational Structure of Sectors of Industry, Labour, vol. 4, no. 3, pp. 3-31.

Eijs, P. van (1993), The Manpower Requirements Approach: Background and Methodology, ROA- RM1993/3E, Maastricht. 
Grip, A. de, J.A.M. Heijke (1988), Labour Market Indicators: an Inventory, ROA-W-1988/1E, Maastricht. Grip, A. de, J.A.M. Heijke, R.J.P. Dekker (1989), The Labour Market by Education and Occupation in 1992, ROA-R-1989/8E, Maastricht.

Grip, A. de, L.F.M. Groot, J.A.M. Heijke (1991), Defining Occupational Groupings by Educational Structure, Environment and Planning A, vol. 23, pp. 59-85.

Grip, A. de, P. Meijboom, E. Willems (1994), Vacancies, Employment Growth and the Demand for Newcomers on the Labour Market, in J. Muijsken (ed.), Measurement and Analysis of Job Vacancies, Maastricht, pp. 101-125.

Hollister R. (1967), A Technical Evaluation of the First Stage of the Mediterranean Regional Project, OECD, Paris.

Loo, P.J.E. van de, R.J.P. Dekker, A. de Grip (1992), Arbeidsmarktsegmentatie als uitgangspunt voor een beroepenclassificatie, Tijdschrift voor Arbeidsvraagstukken, vol. 8, no. 1, pp. 19-31.

Ministerie van Onderwijs en Wetenschappen (1993), Referentieraming 1993, Den Haag.

Parnes H.S. (1962), Forecasting Educational Needs for Economic and Social Development, OECD, Paris.

ROA (1993), The Labour Market by Education and Occupation to 1998, ROA-R-1993/10E, Maastricht.

Sheldon, G. (1985), Die Berufliche und geographische Flexibilität, Institut für Arbeitsmarkt und Berufsforschung, Beitrage ABgz, Nürnberg.

Shryock, H.S., J.S. Siegel (1980), The Methods and Materials of Demography, U.S. Bureau of the Census, U.S. Government Printing Office, Fourth Printing (rev.), Washington D.C.

Teulings, C., M. Koopmanschap (1989), An Econometric Model of Crowding Out of Lower Education Levels, European Economic Review, vol. 33, pp. 1653-1664.

Willems, E.J.T.A., A. de Grip (1993), Forecasting replacement demand by occupation and education, International Journal of Forecasting, vol. 9, pp. 173-185. 